\title{
Experience and Insights of Family Caregivers for Patients with Senile Dementia: A Qualitative Study
}

\author{
Jiamin Chen ${ }^{*}$, Shuyan Zhao ${ }^{*}$, Qinghong Chen ${ }^{2 \#, ~ S h a n g l o n g ~ Y a o ~}{ }^{2 \#}$ \\ ${ }^{1}$ Department of Operation, Hubei Provincial Hospital of TCM, Hubei University of Chinese Medicine, Wuhan, China \\ ${ }^{2}$ Department of Anesthesiology, Union Hospital, Tongji Medical College, Huazhong University of Science and Technology, \\ Wuhan, China \\ Email: " whuhcqh@hust.edu.cn
}

How to cite this paper: Chen, J.M., Zhao, S.Y., Chen, Q.H. and Yao, S.L. (2021) Experience and Insights of Family Caregivers for Patients with Senile Dementia: A Qualitative Study. Health, 13, 1010-1019. https://doi.org/10.4236/health.2021.139076

Received: March 30, 2021

Accepted: September 14, 2021

Published: September 17, 2021

Copyright $\odot 2021$ by author(s) and Scientific Research Publishing Inc. This work is licensed under the Creative Commons Attribution International License (CC BY 4.0).

http://creativecommons.org/licenses/by/4.0/

(c) (i) Open Access

\begin{abstract}
Background: Due to social, economic, cultural and other factors, the majority of dementia patients are taken care of by relatives or nannies at home in China. This family care model puts a heavy burden on caregivers. Objective: The main aim of this article is to explore the experience and needs of caregivers on dementia elderly, reveal the essence, and provide the basis for formulating relevant policies. Methods: A total of 10 caregivers of dementia elderly were intensively interviewed, and data were analyzed by using Colaizzi content analysis methods during May-October 2019. Results: Three themes were extracted from the interviews, including the burden and strain from the care, lack of trust in pension institutions, and experience and comprehension of care. Conclusion: The caregivers have suffered a lot of pressure from taking care of the patients with senile dementia. They lack trust in pension institutions, so it is appealed that targeted services for family caregivers of dementia patients, so as to reduce caregiver burden and improve the quality of care.
\end{abstract}

\section{Keywords}

Dementia, Caregiver, Qualitative Research

\section{Introduction}

Dementia is the number one cause of morbidity in the world, and the number of individuals afflicted with the disease is expected to increase to over 20 million by 
2050. With the aging of the population becoming more and more serious, there are more and more older people who have senile dementia in China. Senile dementia refers to a variety of dementia that occurs over the age of 65 , including Alzheimer's disease, vascular dementia, and mixed dementia [1]. The main manifestations are memory loss, cognitive impairment, behavior and personality changes, some severe cases can be accompanied by mental and emotional disorders, bringing heavy economic and care pressure to society and families [2]. Due to the imperfect health care measures for patients with senile dementia in our country and the influence of traditional culture, more than $90 \%$ of the patients are taken care of by relatives or nannies at home [3]. This long-term family care model puts a heavy burden on caregivers. The purpose of this study is to deeply understand the experience of caregivers of patients with senile dementia, explore their needs, and reveal the deep-seated problems in the process of care, to reduce the burden of caregivers and provide a basis for government agencies to formulate relevant policies.

\section{Method}

\subsection{Participants}

A family caregiver was defined as a person in the family, who had the main responsibility for most daily activities of the person with dementia and caring responsibilities included basic accommodation, daily care, financial support, and accompanying the patient to medical treatment. Purposive sampling was used in this study and the sample size was based on the fact that no new topics appeared in the interview materials. Caregivers were excluded if they suffered from diagnosed organic or psychiatric diseases (e.g., insomnia, depression, and anxiety) before caring for the patients, or they refused to provide authentic and reliable information for the study. Ten caregivers were selected from Wuhan local community and all of the patients received a definitive diagnosis of dementia (based on Diagnostic and Statistical Manual of Mental Disorders, 4th edition, criteria) at neurology clinic of Wuhan hospitals. The data of the subjects are shown in Table 1.

\subsection{Procedures}

The general data were sampled by objective sampling. The phenomenological research method was used, the interview outline was designed in advance, and the data were collected in the form of face-to-face and semi-structured in-depth interviews. Based on reviewing the relevant literature of dementia caregivers, an interview outline is developed according to the purpose of the study: what difficulties did you encounter in the process of care? How did you deal with it? How is your physical and mental state recently? How do you solve the problem if there is pressure? What professional help do you need from the medical staff? What kind of support do you need from other family members, social personnel, and social institutions? 
Table 1. General data of the object of study.

\begin{tabular}{cccccccc}
\hline caregivers & Gender & $\begin{array}{c}\text { Age } \\
\text { (years) }\end{array}$ & Degree & $\begin{array}{c}\text { Number of years } \\
\text { of care (year) }\end{array}$ & $\begin{array}{c}\text { Average daily } \\
\text { care (hours) }\end{array}$ & $\begin{array}{c}\text { Relationship } \\
\text { with patients }\end{array}$ & $\begin{array}{c}\text { Do you have a } \\
\text { nursing background? }\end{array}$ \\
\hline 1 & Female & 54 & Junior college & 3 & 8 & Mother-in-law & Yes \\
2 & Female & 32 & Junior college & 2 & 8 & grandparents and grandchild & Yes \\
3 & Female & 22 & Junior college & 1 & 8 & grandparents and grandchild & Yes \\
4 & Female & 49 & Junior college & 3 & 8 & Father and daughter & Yes \\
5 & Female & 50 & Junior college & 8 & 8 & Father and daughter & Yes \\
6 & Female & 70 & Primary school & 2 & 24 & Husband and wife & No \\
7 & Female & 30 & Junior college & 1 & 4 & grandparents and grandchild & No \\
8 & Female & 66 & Junior middle school & 2 & 24 & Husband and wife & No \\
9 & Male & 61 & Junior middle school & 4 & 24 & Father and son & No \\
10 & Female & 57 & Primary school & 2 & 24 & Mother and daughter & No \\
\hline
\end{tabular}

Before the interview, the researcher first introduced the purpose, method, and content of the study to the subjects, obtained understanding and consent, signed an informed consent form, and promised to replace names with codes to protect their privacy. Agree on the time and place of the interview. Choose a quiet and private environment for each interview for 30 - 60 minutes. During the interview, the method of recording and recording was adopted, and at the same time, the interviewees' facial expressions and body movements were carefully observed.

\subsection{Data Collection and Analysis}

The recordings and records were transcribed into words within 24 hours after the interview, and analyzed according to the qualitative research analysis of Colaizzi [4], including carefully reading the interview records, extracting statements of significance, coding repeated views, pooling the encoded views, writing a complete description, identifying similar views, and seeking verification from the interviewees [5].

\section{Results}

Through the analysis of the data, we extracted three themes from all the interviews: burden and strain from the care, lack of trust in pension institutions, and experience and comprehensions of care, as shown in Table 2.

\subsection{Theme I Burden and Strain from the Care}

Firstly, with the development of the disease, dementia elderly People's Daily life ability gradually decline, dependent on the caregiver more and more. Most of the caregivers were the sole full-time caregiver and had little time for themselves. Caring for dementia patients not only took up time and energy, but also disrupted their lives and made them feel particularly tired. Personal time of 
Table 2. Experience and insights of home caregivers for patients with senile dementia.

\begin{tabular}{|c|c|c|}
\hline Theme & Experience & Insights of home caregivers \\
\hline \multirow{3}{*}{$\begin{array}{l}\text { Burden and } \\
\text { strain from } \\
\text { the care }\end{array}$} & $\begin{array}{l}\text { Personal time limit. Family members } \\
\text { affected by entertainment activities. }\end{array}$ & $\begin{array}{l}\text { Family member 1: "Limited to one position, one mode every day, } \\
\text { I can't go out, can't do anything, but take care of the patient day and night. } \\
\text { There is no communication with her." } \\
\text { Family member 4: "I used to like running. I haven't run since my father } \\
\text { got sick. I used to travel with my husband, but now I can't go out." } \\
\text { Family member 6: "I dare not leave him for fear of an accident to him. } \\
\text { I used to go out for square dancing, but now I can't go. I have to watch him." } \\
\text { Family member 7: "Now I keep looking at her for fear that something } \\
\text { bad may happen to her." }\end{array}$ \\
\hline & $\begin{array}{l}\text { The communication and relationship } \\
\text { between family members are affected. }\end{array}$ & $\begin{array}{l}\text { Family member 4: "There are some things I can't say to my sister. } \\
\text { I feel disgusted with my father if I talk too much. Telling my mother that } \\
\text { she doesn't understand and feels psychologically inseparable. Originally, } \\
\text { I made an agreement with my mother to let my father go to the hospital, } \\
\text { but my eldest sister came and stopped it. She was in the countryside and } \\
\text { didn't know much about the disease. She said that our father would } \\
\text { not go to the hospital if he didn't admit the fact he was ill. I was very } \\
\text { uncomfortable, but I'm not the boss and my words didn't carry any weight." } \\
\text { Family member 5: "Knowing that our family conditions are good, my parents } \\
\text { have salaries, and people who sell health products often come to our home to } \\
\text { chat. They have spent a lot of money on health products alone, and they don't } \\
\text { listen to me. It is not easy to care for the elderly, while my brothers and sisters } \\
\text { also make trouble with each other, my mother does not understand. Now my } \\
\text { brother is retired and takes care of the elderly at home. My father's salary card } \\
\text { has also been given to him, but my mother still asks us for money and gave it to } \\
\text { my brother. I was very angry." } \\
\text { Family member 10: "I serve my mother all the time. People thought I was an } \\
\text { only child, but actually I had several brothers and sisters." }\end{array}$ \\
\hline & Lack of relevant nursing knowledge & $\begin{array}{l}\text { Family member 5: "He sleeps upside down, does not sleep at night, } \\
\text { sleeping during the day tortures people." } \\
\text { Family member 6: "How can he get better with this disease? } \\
\text { How do you think you can treat it?" } \\
\text { Family member 8: "He doesn't sleep at night, but he sleeps during the day. } \\
\text { Is there any way to change it?" } \\
\text { Family member 9: "I think the less I communicate with others, the higher } \\
\text { the probability of getting dementia." I hope to provide me with professional } \\
\text { nursing knowledge." } \\
\text { Family member 10: "I don't know anything about this disease, and } \\
\text { I don't know how to take care of my mother, especially incontinence. } \\
\text { Is there any good nursing method?" }\end{array}$ \\
\hline $\begin{array}{l}\text { Lack of trust in } \\
\text { pension } \\
\text { institutions }\end{array}$ & & $\begin{array}{l}\text { Family member 1: "The nursing home can't take care of herself in all aspects, } \\
\text { so we are worried that pension institutions can't take care of her well. It is } \\
\text { better to hire a nanny so that the elderly can be better taken care of. } \\
\text { I have a relative who also has Alzheimer's disease. Nobody could take care } \\
\text { of him at home. He died three months after he was sent to a nursing home." } \\
\text { Family member 4: "My younger sister said that my father has a salary and he } \\
\text { should be sent to a nursing home, but I'm afraid my father can't be taken } \\
\text { care of in a nursing home. But my older sister thinks it costs too much to } \\
\text { send to a nursing home." }\end{array}$ \\
\hline
\end{tabular}




\section{Continued}

Family member 5: "My mother is reluctant to send my father to a nursing home because she is worried about the condition there. My brother also thinks it costs too much to send to a nursing home."

Family member 6: "I didn't want to go to a nursing home.

I'll just take care of the patient myself."

Family member 1: "When the patient doesn't eat well, or when he doesn't eat, I will say to him that the food was given by the doctor. If you don't listen, the doctor won't treat you."

Diet care Family member 2: "I just coax her, this is what you like to eat, this is candy, sometimes she doesn't not eat at the right time, I will give it to him later."

Family member 4: "The patient seems doesn't know if he is full already. I just feed him a certain amount of food."

Family member 1: "Put open-crotch pants on her, like a child, I estimate her time to pee, then take her to the toilet chair."

Excretion care

Family member 5: "I bought him a wheelchair and a toilet. I also bought a hairdresser and a razor to clean up for him, which is better than what he did himself."

Family member 1: "In order to exercise her fingers, I give her a box with paper in it, tell her to clean it up, and she would tear or tidy up the paper."

Exercise

Family member 3: "I tell her to raise her hand when she wants to pee."

Family member 4: "He used to be a cashier and liked to calculate,

Experience and comprehensions of care but now I use a small book for him to calculate."

Family member 1: "When she was folding the paper, I told her that what she did was really good, that the leader of our city praised you, then she was extremely happy about the compliment. Give her a thumbs up, she is also extremely happy, just like coaxing a child."

Family member 4: "He was disobedient and angry, so I ignored him and hid. When he's not angry, I'll joke with him again.”

Family member 1: "I often nurse her so I know that when she has to urinate, when she takes paper or grabs something else,

Carefulness and patience or scratches her hand on her waist, then I know what she is going to do."

Family member 2: "In taking care, you should be careful and learn to explore experience."

Family member 3: "Sometimes one same question is asked several times. I understand that is due to the illness."

Family member 2: "At the beginning of care, I didn't not adapt, with the passage of time, I have to adjust the state of my mind."

Self-adjusting Family member 3: "If you can't accept it at first, adjust your mindset slowly." Family member 9: "Sometimes when I was taking care of him, he suddenly hit me. I couldn't accept and stand it. I adjusted my mindset."

caregivers is limited and recreational activities are affected. Thus, caregivers often felt enormous pressure on care because they considered that they had little time for themselves. Secondly, Family members who care for Alzheimer's sometimes didn't understand each other because of the different understanding of the 
disease, especially in the families with many members. Other members often failed to understand the feelings of the person in charge of caring for the elderly with dementia, communication and relationships among family members were affected. Thirdly, in the interviews, some family members did not understand the process of this disease and lacked relevant nursing knowledge. There is an urgent need for them to know how to care for dementia better.

\subsection{Theme II Lack of Trust in Pension Institutions}

Some caregivers were reluctant to send them to pension institutions or nursing homes, mainly because they were worried about the quality of care there and they thought it was best to take care of the patients at home. On the other hand, they were also worried about that the costs there are too high and they were not able to afford it, which also increased their distrust of pension institutions.

\subsection{Theme III Experience and Comprehensions of Care}

Caregivers believed that caring for patients with senile dementia should be cautious and patient, Caregivers had to treat elderly people with dementia like children, which always needed more attention to communication, strengthen diet and excretion care. In addition, some caregiver admitted that self-regulation was also important to have a healthy mindset to take care of patients.

\section{Discussion}

\subsection{Reduce the Burden and Strain from Care}

This study shows that caregivers are under heavy pressure to take care of the patients. Due to the special condition of the patients with senile dementia, the caregivers are physically and mentally exhausted, which was significantly related with impaired quality of life in domains of physical, social, psychological, and environment. And due to lack of professional knowledge of the disease and nursing knowledge [6], family members are easy to have differences on how to treat the patients right, which affects the family relationship. This is consistent with Wu Jun's research [7].

It is suggested that community daycare centers and short-term care institutions for Alzheimer's patients should be established in the community. Providing such services for patients with Alzheimer's disease can enable caregivers to have a certain amount of time and space, and get short-term relaxation. At the same time, patients with Alzheimer's disease can also receive professional nursing care. It might be possible that government set up special institutions to receive Alzheimer's patients in the region, such as dementia care units. When Alzheimer's patients can't get care at home, they can stay in professional nursing institutions [8].

With regard to the disease itself, cognitive deterioration and the loss of self-care ability as dementia progresses consume more time and energy of the caregiver. Therefore, more focus has to be placed on rehabilitation in earlier stages of de- 
mentia. Many cognitive rehabilitation methods have been considered to be effective, such as cognitive stimulation therapy, light therapy, aromatherapy, nutritional supplementation, and psychological treatment [9]. We can make full use of the resources of community health service institutions to improve residents' understanding of senile dementia by carrying out health education, distributing publicity materials and family visits. Network technology can also be used to provide help to caregivers of dementia. Lu Xiaofan et al. [10] reviewed the application of network technology in the intervention of caregivers of senile dementia, such as network information support. Through the online platform to provide caregivers with general health knowledge and related information, such as senile dementia disease-related knowledge, care skills, disease treatment research progress, social help resources, and so on. This network also would be conducive to dementia caregivers in the family to gain more understanding and support, the establishment of a harmonious family atmosphere, to reduce their burden [11].

\subsection{Improve Pension Institutions, Vigorously Develop the Combination of Medical Care and Nursing Care, and Strengthen the Professional Construction of Nursing Staff}

Cultural elements and social and health care environments lead to the traditional way of caring, which remains the preferred choice in China. Despite the heavy burden, all the caregivers chose to continue caring for patients in their family. In the current study, many family members are reluctant to send Alzheimer's patients to pension institutions. There are some reasons: 1) there is a misunderstanding of such institutions as nursing homes for the aged, and people are worried that patients with senile dementia may not be taken care of very well; 2) enormous economic pressure, especially those families with poor economic conditions, they can't afford the expenditure; 3 ) under the influence of China's traditional filial piety culture and family concept, children should take care of the elderly, support the elderly, and send them to pension institutions is a manifestation of unfilial loyalty, and the pressure of moral public opinion is high. They do not want to be separated from the elderly, especially those taken care of by their spouses. Thus, it is suggested that the government and the whole society should pay more attention to improve pension institutions and vigorously develop the combination of medical care and nursing care. We can make full use of media, community activities, slogans, and other forms to change people's traditional concept of providing for the aged, cultivate the whole people's ideology of "healthy aging", and create an excellent social atmosphere for the development of the combination of medicine and nursing. On the other hand, the institutional orientation of the integrated medical and nursing service should be set up to meet the demographic structure and actual pension needs of the region. It will be challenging to meet the pension service needs of ordinary income families and affect the occupancy rate. Furthermore, strengthen the professional construction of the nursing team, improve the quality of medical care, so that family 
members can rest assured to send the elderly to nursing homes. In the long run, medical colleges and universities can offer relevant majors or corresponding courses to train professionals engaged in medical care for the elderly. In the short term, we can rely on the government and specialist hospitals to set up a training center for nursing workers for patients with Alzheimer's disease to provide professional care personnel for home and daycare centers. The old-age service of the combination of medicine and nursing is a kind of specialized service, so it is imperative to carry out multi-level nursing education for the aged [12].

\subsection{Experience and Comprehensions of Caregivers}

In the present study, several caregivers are family members with a nursing background and have accumulated a lot of successful care experience in the process of care. We suggest that community health service organizations organize regular exchange sessions for caregivers of dementia so that experienced caregivers could share their care experience, and this is also an opportunity to help each other and exchange experiences, and promote the sharing of care feelings and care skills among caregivers, especially for the caregivers who just starts. $\mathrm{Wu}$ Yuanyuan et al. [13] found that the level of perceived benefits of the primary caregivers of patients with Alzheimer's disease was low. Therefore, caregivers are encouraged to join mutual aid organizations, make full use of all kinds of resources, and make positive changes in personal growth, self-efficacy, psychological resilience, social support, and so on, to establish a correct concept of care and improve negative emotions, improve their quality of life and the quality of care as well. At the same time, through regular gatherings, caregivers can also relieve mental stress, and increase their sense of belonging and self-confidence through group venting and mutual learning [14].

\section{Limitation}

There are some limitations in this study. Because of the research method used and the small sample size, and the specific content of the interview can only represent the experience of local caregivers, this study may not cover all the situations. Thus, there is a need for a broader range of research in the future.

\section{Summary}

By using the method of qualitative research, this study deeply interviewed the real experience of 10 local caregivers of patients with senile dementia and described the heavy care pressure of caregivers, lack of trust in pension institutions, experience and comprehension of caregivers and other problems. It reveals the deep-seated reasons. Some suggestions are proposed based on analysis to call the whole community to pay more attention and help. It is needed to create an environment with stronger support for developing healthcare resources for the elderly, programs to train skilled caregivers, and education on 
coping strategies for different medical conditions.

\section{Acknowledgements}

This study was supported by grants from the National Natural Science Foundation of China (No. 81501641).

\section{Conflicts of Interest}

The authors declare no conflicts of interest regarding the publication of this paper.

\section{References}

[1] Li, Z. (2011) Discrimination of Related Concepts of Senile Dementia. Chinese Journal of Nursing, 46, 1045.

[2] Cotter, V.T. (2007) The Burden of Dementia. The American Journal of Managed Care, 13, 193-197.

[3] Zhang, Z.X., Chen, X., Liu, X.H., et al. (2004) Investigation on Health Care Status of Dementia Patients in Beijing, Xi'an, Shanghai and Chengdu. Journal of the Chinese Academy of Medical Sciences, 26, 116-121.

[4] Li, Z. and Liu, Y. (2012) Nursing Research Methods. People's Health Publishing House, Beijing.

[5] Zhang, X.Q. (2012) A Qualitative Study on the Misunderstanding of Self-Management in Patients with Diabetes Mellitus. Nursing Research, 26, 2137-2138.

[6] Wang, J., Xiao, D.X., Yao, W., et al. (2014) Burden of Family Caregivers in Patients with Senile Dementia and Its Coping Strategies. Chinese Journal of Gerontology, 34, 2295-2297.

[7] Wu, J., Yu, Y., Zhou, Q., et al. (2010) Phenomenological Analysis of the Experience of Caregivers of Senile Dementia in the Community. Chinese Journal of Social Medicine, 27, 215-216.

[8] Hao, W., Wu, J., Zhang, H., et al. (2015) Study on Supportive Care Needs of Family Caregivers of Patients with Senile Dementia at Home. Nursing Management in China, 15, 1294-1297.

[9] Dourado, M.C.N. and Laks, J. (2016) Psychological Interventions for Neuropsychiatric Disturbances in Mild and Moderate Alzheimer's Disease: Current Evidences and Future Directions. Current Alzheimer Research, 13, 1100-1111. https://doi.org/10.2174/1567205013666160728143123

[10] Lu, X.F., Zhu, H.R. and Zeng, H. (2015) Application of Network Technology in the Intervention of Caregivers of Senile Dementia. Journal of Nursing, 30, 109-112.

[11] Ji, P., Xiao, S.Z. and Sun, P. (2010) A Qualitative Study on the Care Feelings of Non-Employed Female Caregivers in Patients with Dementia at Home. Journal of Nursing Management, 10, 787-789.

[12] Shen, G. and Dai, M. (2018) Keep Pace with the Times and Innovate the Thinking of Geriatrics. Chinese Journal of Clinical Health, 21, 1-3.

[13] Wu, Y.Y., Pan, L., Deng, L. and Wang, J.Y. (2019) Correlation between Perceived Benefits and Empirical Avoidance of Main Caregivers in Patients with Senile Dementia. Journal of Nursing, 34, 31-34.

[14] McHugh, J.E., Wherton, J.P., Prendergast, D.K. and Lawlor, B.A. (2012) Teleconfe- 
rencing as a Source of Social Support for Older Spousal Caregivers: Initial Explorations and Recommendations for Future Research. American Journal of Alzheimer's Disease and Other Dementias, 27, 381-387.

https://doi.org/10.1177/1533317512453491 